\title{
Successful use of TNFa blockade in a severe case of idiopathic non- granulomatous ulcerative jejunoileitis associated with thrombotic thrombocytopenic purpura
}

\author{
Fabian Braun, ${ }^{01,2}$ Victor Suarez, ${ }^{1}$ Johanna Dinter, ${ }^{3}$ Stefan Haneder, ${ }^{4}$ \\ Alexander Quaas, ${ }^{5}$ Thomas Benzing, ${ }^{1}$ Dirk Nierhoff, ${ }^{3}$ Roman-Ulrich Müller ${ }^{1}$
}

To cite: Braun F, Suarez V, Dinter J, et al. Successful use of TNF $\alpha$ blockade in a severe case of idiopathic non-granulomatous ulcerative jejunoileitis associated with thrombotic thrombocytopenic purpura. BMJ Open Gastro 2019;6:e000252. doi:10.1136/ bmjgast-2018-000252

- Additional material is published online only. To view please visit the journal online (http://dx.doi.org/10.1136/ bmjgast-2018-000252).

FB and VS contributed equally.

DN and R-UM are joint senior authors.

Received 18 0ctober 2018 Revised 26 December 2018 Accepted 1 January 2019

\section{Check for updates}

(c) Author(s) (or their employer(s)) 2019. Re-use permitted under CC BY-NC. No commercial re-use. See rights and permissions. Published by BMJ.

For numbered affiliations see end of article.

Correspondence to Dr Roman-Ulrich Müller; roman-ulrich.mueller@ukkoeln.de

Dr Dirk Nierhoff; dirk.nierhoff@uk-koeln.de

\begin{abstract}
We describe the case of 50-year-old female patient who presented with severe gastrointestinal symptoms and progressive weight loss of unknown origin. Shortly after admission, she developed an acute flare of thrombotic thrombocytopaenic purpura (TTP) that had to be treated by plasma exchange therapy and rituximab administration. While the signs of TTP subsided, the gastrointestinal symptoms worsened with abdominal cramps, massive gastric retention, malnourishment and a stenosis due to extensive inflammation and wall thickening of the small bowel. Extensive diagnostic efforts yielded no specific cause, so the patient-based on the histopathological findings - was diagnosed with idiopathic non-granulomatous ulcerative jejunoileitis. Following a highly complicated clinical course over several months, successful remission of the inflammatory activity and recovery of the patient could be obtained by TNF-alpha blockade.
\end{abstract}

Idiopathic non-granulomatous ulcerative jejunoileitis is a diagnosis of exclusion. Due to the rarity of this disorder, the underlying pathogenetic cause is not clear. Here, we present the first case of idiopathic non-granulomatous ulcerative jejunoileitis coinciding with thrombocytopaenic purpura (TTP). The example of successful treatment with infliximab in such a complicated and life-threatening case may help to provide a potential approach in similar future cases.

We report the case of a 50-year-old woman who presented with unintended weight loss due to progressive loss of appetite, nausea, vomiting and diarrhoea in March 2016. The patient had no relevant medical history, apart from a Helicobacter pylori (HP)-positive gastritis in 2015.

Biopsies taken in a gastroscopy tested positive for HP again (table 1), so she was started on Metronidazole, Clarithromycin and Pantoprazole. Further diagnostics did not yield any additional insights into the cause of her symptoms. Shortly after the initiation of therapy, she developed fever accompanied by a Coombs negative haemolytic anaemia (haemoglobin $8.2 \mathrm{mg} / \mathrm{L}$ ), a rise in schistocytes $(25 \%$ ) and a concurrent drop of thrombocytes down to $7.000 / \mu 1$, suggestive of TTP. Plasmapheresis was started immediately. While heparin-induced thrombocytopaenia was ruled out, the enzyme activity of ADAMTS-13 was reduced to $5 \%$ with an anti-ADAMTS-13-antibody concentration of 66.0 U/mL confirming the diagnosis of TTP. Consequently, plasmapheresis was continued until normalisation of thrombocytes. Furthermore, a 3-day course of high-dose dexamethasone was administered. Despite this treatment, TTP recurred 10 days later leading to another course of plasmapheresis with the administration of $1 \mathrm{~g}$ rituximab. While thrombocyte count and haemoglobin remained at a low but stable level and haptoglobin returned to the normal range afterwards, the initial gastrointestinal symptoms (nausea, vomiting and diarrhoea) continued and worsened cumulating in abdominal cramps requiring high-dose opioids for pain control. Extensive bacteriological and virological screenings did not yield an infectious cause (see online supplementary material S1). Gastroscopy and an upper gastrointestinal X-ray series showed impaired peristalsis with consecutive gastric retention while histology tested negative for HP-associated gastritis indicating successful eradication. Due to continued emesis, the patient received a nasogastric and later nasojejunal tube. Despite the initiation of parenteral feeding, she developed progressive hypalbuminemia-assumably 
Table 1 Diagnostic procedures and results obtained

\begin{tabular}{|c|c|c|}
\hline \multirow[t]{3}{*}{$03 / 2016$} & Gastroscopy & HP-positive chronic gastritis type $A$ \\
\hline & CT thorax & $\begin{array}{l}\text { Lymph nodes of a maximum diameter of } 1 \mathrm{~cm} \text {, subpleural } \\
\text { consolidations }\end{array}$ \\
\hline & CT abdomen & Dysontogenetic liver cysts \\
\hline \multirow[t]{5}{*}{ 03/29/2016 } & ADAMTS-13 activity & $5 \%$ \\
\hline & ADAMTS-13 antibody & $66.0 \mathrm{IU} / \mathrm{mL}$ \\
\hline & ANCA, dsDNA, C3, C4, Rheumatoid factor & Negative \\
\hline & ANA & Positive without specific subtype \\
\hline & HIT 2 ELISA & Negative \\
\hline \multirow[t]{7}{*}{ 03/29/2016 } & $\begin{array}{l}\text { Hepatitis B serology (HBV-Surface-AG, HBV- } \\
\text { Core- } A b)\end{array}$ & Negative \\
\hline & Hepatitis C serology & Negative \\
\hline & HIV serology & Negative \\
\hline & CMV serology & IgM negative, IgG $140 \mathrm{IU} / \mathrm{mL}$ \\
\hline & VZV serology & Negative \\
\hline & HSV serology & Negative \\
\hline & Parvovirus B19 serology & Negative \\
\hline 03/30/2016 & $\begin{array}{l}\text { Stool PCR for Astrovirus, Norovirus, Rotavirus, } \\
\text { adenovirus }\end{array}$ & Negative \\
\hline 03/31/2016 & PET CT & Pleural effusions, bone marrow activity \\
\hline \multirow[t]{2}{*}{ 03/30/2016 } & $\begin{array}{l}\text { Stool culture for Shigella, Salmonella, Yersinia, } \\
\text { Campylobacter }\end{array}$ & Negative \\
\hline & Stool PCR for Clostridium difficile, E. coli & Negative \\
\hline 04/08/2016 & Antiphospholipid-Syndrome & Negative \\
\hline 05/03/2016 & Serology and PCR for CMV & IgM negative, IgG >250 IU/mL, 9960 IU/mL \\
\hline \multirow[t]{2}{*}{ 05/10/2016 } & Biopsy PCR for Tropheryma whippelii & Negative \\
\hline & $\begin{array}{l}\text { Biopsy immunohistochemistry for } \\
\text { Mycobacterium tuberculosis }\end{array}$ & Negative \\
\hline 05/11/2016 & Intestinoscopy & $\begin{array}{l}\text { Severe enteritis (figure 1D), polyclonal TCR pattern: no T-Cell } \\
\text { Lymphoma }\end{array}$ \\
\hline 05/18/2016 & Blood PCR for CMV & Negative \\
\hline 05/26/2016 & MRI Sellink & $\begin{array}{l}\text { Ubiquitary enhancement of contrast agent in stomach and } \\
\text { small intestine with maximum in jejunal part (figure } 1 A, B)\end{array}$ \\
\hline 06/08/2016 & Blood PCR for CMV & $10400 \mathrm{IU} / \mathrm{mL}$ \\
\hline 06/15/2016 & Blood PCR for CMV & Negative \\
\hline \multirow[t]{2}{*}{$07 / 25 / 2016$} & HLA DQ2 & Negative \\
\hline & HLA DQ8 & Negative \\
\hline \multirow[t]{2}{*}{ 09/14/2016 } & Intestinoscopy & Severe enteritis \\
\hline & Anti-HLA60-Ab & Positive \\
\hline 09/18/2016 & cMRI & Oedema of the thalamic area \\
\hline \multirow[t]{2}{*}{ 09/22/2016 } & Aspirate and trepanate & $\begin{array}{l}\text { Hypocellular bone marrow aspirate due to azathioprin toxicity, } \\
\text { normocellular bone marrow trapanate }\end{array}$ \\
\hline & Blood PCR for CMV & $9 \mathrm{IU} / \mathrm{mL}$ \\
\hline 09/27/2016 & Autoimmune encephalitis & Negative \\
\hline 09/30/2016 & Blood PCR for CMV & $578 \mathrm{IU} / \mathrm{mL}$ \\
\hline $10 / 06 / 2016$ & Blood PCR for CMV & Negative \\
\hline $10 / 25 / 2016$ & Intestinoscopy & Severe enteritis with new stenosis $120 \mathrm{~cm}$ aboral (figure 1E) \\
\hline
\end{tabular}


Table 1 Continued

12/12/2016 Intestinoscopy

Reduction of known subtotal stenosis decreasing sign of

inflammation (figure 1G)

ANA, anti-nuclear autoantibodies; ANCA, anti-neutrophilic cytoplasmic autoantibodies; CMV, cytomegalovirus; HLA, human leukocyte antigen; HSV, herpes simplex virus; SLE, systemic lupus erythematodes; VZV, varicella zoster virus; vWF, von-Willebrand factor.

as a consequence of exudative enteropathy with severe leakage through inflamed mucosal lesions-accompanied by anasarca. We performed a colonoscopy detecting a CMV-positive chronic ileitis. Ganciclovir was initiated, successfully clearing the blood from CMV DNA copies (table 1), but the patient remained symptomatic. Therefore, we extended our diagnostic efforts to an intestinoscopy showing severe enteritis with ulcers, mucosal oedema and increased vulnerability to contact starting $90 \mathrm{~cm}$ aborally at the transition of jejunum to ileum (figure 1D). In summary of all histological findings there were no indications of Crohn's disease - a possible underlying pathology in this setting. The biopsies were dominated by ulcerations and reactive epithelial changes with loss of goblet cells but missed the Crohn's typical 'focal active and focal chronic'-inflammation pattern. One of Crohn's typical histological sign, the so-called 'focal chronic inflammation', considering focal areas of dense lymphoplasmacellular infiltrates intermingling the whole mucosa thickness, was not detectable, nor were granulomas.

This lead us to suspect-despite negative antibody screening-an atypical refractory coeliac disease. To exclude any further food allergies or intolerances, we discontinued oral feeding and administered high-dose prednisolone. Symptoms started to improve and we were able to start tapering the steroid dosage by combining the therapy with azathioprine. Further diagnostics for an underlying infectious or malignant cause (see online supplementary file 1) remained negative. Under immunosuppressive therapy, we were able to reinitiate oral ingestion of a lactose-free and gluten-free diet. The pain was adequately controlled with low doses of percutaneous fentanyl. On 26 July, she was discharged for further medical rehabilitation.

On 14 August, the patient had to be readmitted to our hospital and was in critical condition. Overall pain, nausea, vomiting, diarrhoea and malnourishment had worsened again with progressive hypalbuminemia and anasarca. We implanted a port-catheter system and started intravenous refeeding. To taper steroid doses, oral azathioprine was changed to intravenous administration that, shortly afterwards, had to be discontinued due to pancytopaenia (with marked thrombocytopaenia). Recurrent TTP, as well as HIT, was ruled out and a bone marrow biopsy confirmed toxic damage. In September, the patient reported progressive vertigo followed by an upbeat nystagmus. MRI scans depicted an oedema of the
A

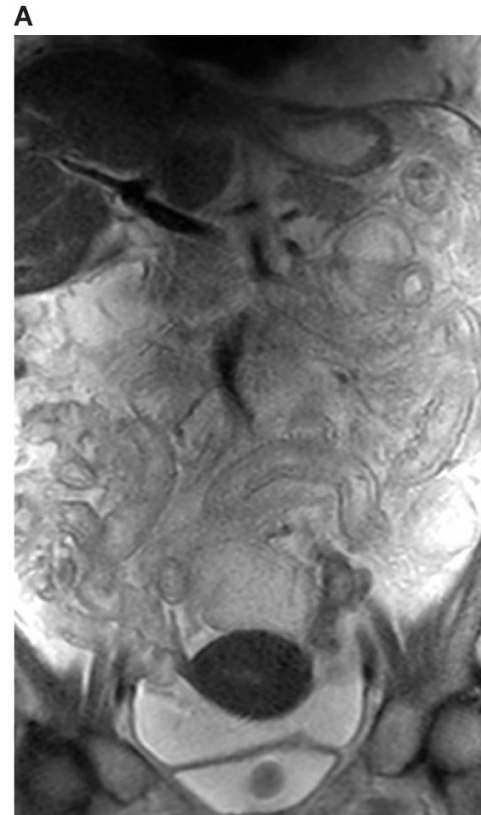

B

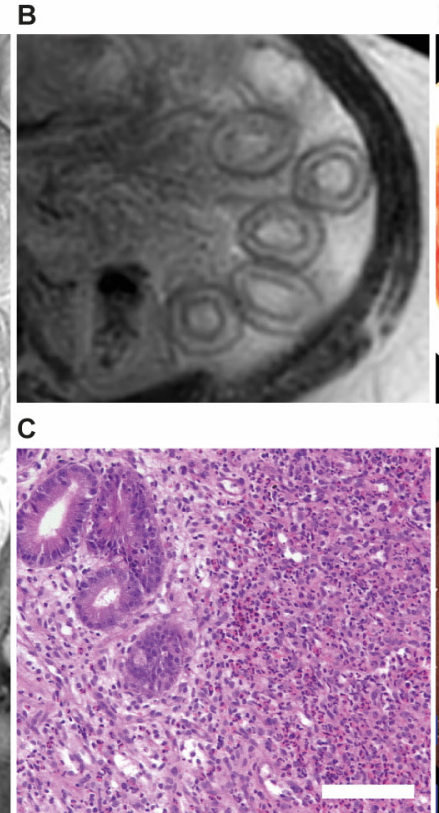

D

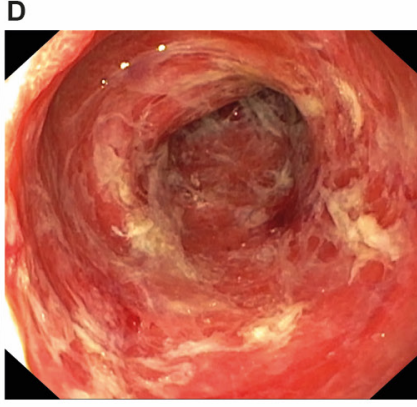

E

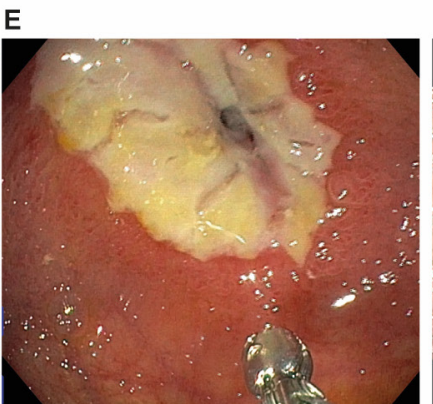

$\mathbf{F}$

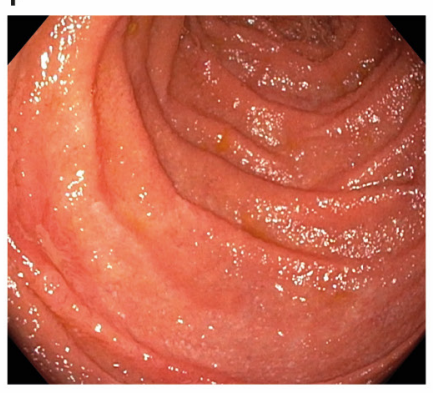

G

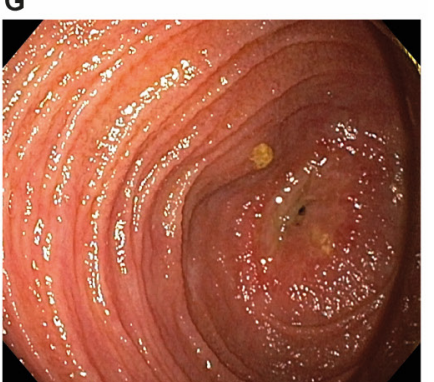

Figure 1 Radiological, macroscopic and histological appearance of idiopathic non-granulomatose ulcerative jejunoileitis (A) MR Sellink depicting massive wall thickening of the entire small intestine in coronary slice. (B) Enhanced view on jejunoileal wall thickening in transversal slice. (C) Small bowel biopsy with uncharacteristic ulceration of the mucosa including mixed inflammatory cell infiltrate in the lamina propria, size bar indicating $100 \mu \mathrm{m}$. (D) Intestinoscopy depicting haemorrhagic inflammation with membranous detachment of inflamed mucosal layer. (E) Ulcerative stenosis. (F) Healed and restored normal mucosa in intestinoscopy after two courses of TNF $\alpha$ blockade. (G) Stenosis after four courses of TNF $\alpha$ blockade. 
thalamic area, suggestive of Wernicke's encephalopathy. Despite the previous supplementation of vitamins, thiamine levels were low. Thus, we started her on high-dose intravenous thiamin.

Though treated with high-dose steroids, abdominal pain worsened accompanied by several episodes of paralytic ileus under opioids and consecutive peritonitis with fever and muscle spasms. Consequently, we implanted a thoracic epidural catheter for further analgesic therapy, which brought great relief to the patient and allowed for a substantial reduction of systemic opioids.

An additional intestinoscopy revealed severe (and worsening) enteritic lesions with no detectable effect of the current immunosuppressive therapy. Furthermore, a subtotal inflammatory stenosis at $120 \mathrm{~cm}$ from the teeth line was detected (figure 1E), most probably responsible for the abdominal cramps and recurrent symptoms of mechanic (sub)ileus. Due to the overall disease state and the severe inflammation of the surrounding intestinal mucosa, a surgical resection of the stenotic area was not a viable option. Taking into account the histopathological changes showing chronic uncharacteristic ulcerations of the small bowel mucosa without granuloma or signs of vasculitis (figure 1C) and the severity of the disease (complete immobility, continuous weight loss, malnourishment, Wernicke's encephalopathy and inflammatory stenosis) with all differential diagnoses having been ruled out (see online supplementary material S1), the diagnosis of an idiopathic non-granulomatous ulcerative jejunoileitis remained by exclusion. Due to the rarity of this diagnosis, the best approach to therapy is not clear. However, previous reports had shown a potential benefit of TNF-alpha antagonists. Consequently, we started the patient on infliximab. While a control intestinoscopy after 3 weeks showed no initial benefit, the clinical state improved drastically. Pain, nausea and diarrhoea subsided and we were able to start oral food administration. In December 2016, the intestinal mucosa clearly showed decreasing signs of inflammation while the stenosis had only partly resolved (figure 1G), suggestive of a remodelling of the intestinal wall due to chronic inflammation. In the meantime, along with the improvement of inflammation, clinical symptoms have subsided and the patient is eating normally. She is mobile (after having been bedridden for many months), free from pain or neurological symptoms and continuously gaining weight (body mass index February 2017: 17; June 2018: 21). Furthermore, her vitamin levels have normalised and serum albumin (March 2017: 15 g/L; June 2018: 20 $\mathrm{g} / \mathrm{L}$ ) has been continuously increasing, demonstrating improved absorption and nutrition. At the moment, she is in out-patient care receiving infliximab infusions every month with the interval being slowly prolonged. The port catheter system could be explanted; bloodwork, sonography and intestinoscopy do not indicate any signs of recurrent inflammatory activity.

Non-granulomatous ulcerative jejunoileitis is an extremely rare condition. So far only five cases have been reported in the literature. ${ }^{1-5}$ The disease's pathology remains largely elusive. Clinical and experimental data point to an involvement of the TNF-alpha pathway and beneficial effects on its inhibition. ${ }^{56}$

In the case of our patient, the combination of this diagnosis with TTP was a peculiar finding complicating the clinical course. TTP is-apart from rare hereditary cases-an acquired autoimmune disease with the formation of antibodies against the vWF-cleaving protease ADAMTS-13, which - through the formation of big vWF-multimers leads to an impairment of the patient's microcirculation.

The coincidence of TTP with other autoimmune-diseases like systemic lupus erythematosus or rheumatoid arthritis has been described before. A thorough study was conducted by a French register-based trial in $2015 .{ }^{7}$ SLE and Sjögren syndrome were the most common among the accompanying diseases, but cases of inflammatory bowel disease (IBD) before and after the episode of TTP were also described. Well-documented cases of TTP co-occurring with IBD are rare. Almogy et al reported the case of a young patient who was hospitalised because of a rapidly ensuing ulcerative colitis that did not respond to prednisolone or 5 -ASA. ${ }^{8}$ The patient underwent subtotal colectomy and developed symptoms of a thrombotic microangiopathy that was identified as TTP shortly after surgery. Despite rapid initiation of plasmapheresis symptoms prevailed and it was only after emergent splenectomy and proctectomy that haemolysis stopped. ${ }^{8}$

A case of TTP during an acute flare of Crohn's disease primarily refractory to standard treatment is described by Schleinitz et al. ${ }^{9}$ Gastrointestinal symptoms, as well as haemolysis, vanished shortly after initiation of plasmapheresis. Generally, Crohn's disease cannot be easily ruled out in our a case. However, we could not find classical signs of Crohn's disease in any of the numerous biopsies as described above.

It is important to note that thrombosis of the microcirculation itself can mimic symptoms of IBD through chronic ischaemia if TTP is not recognised.

IBD leads to an activation of all components of the coagulation cascade. A significant increase of both venous and arterial thrombotic events has been reported for patients with IBD. ${ }^{10}$ This is due to the latent immunological activation as well as a chronic activation of platelets, which leads to enhanced formation of platelet-leucocyte aggregates. ${ }^{11}$

Molecular studies on the underlying mechanisms of either TTP or ulcerative jejunoileitis are scarce due to the rare occurrence of both conditions. A link for both diseases in our case might be the activation of the TNF-alpha cascade. In 1995, Karpman et al conducted a small study investigating TNF-alpha serum levels in children with haemolytic uremic syndrome and TTP. ${ }^{12}$ Interestingly, they found elevated serum TNF-alpha in children with recurrent TTP. Since the patient described in this report is currently successfully treated 
with TNF-alpha blockade by infliximab, we would speculate the non-granulomatous ulcerative jejunoileitis with an increase in TNF-alpha levels to be a potential additional trigger for the ensuing TTP. Besides, the patient was initially treated with metronidazole, an antibiotic that has been suggested as a cause for TTP in one case. ${ }^{13}$ Nonetheless, we consider this treatment unlikely to be the cause of TTP, as the patient suffered a relapse 10 days after successful plasmapheresis when treatment with metronidazole had long been discontinued.

Further data from in vitro and in vivo studies show that CD40L, another protein of the TNF-superfamily, which is expressed by activated T-cells, macrophages and platelets, could be an essential ligand between inflammation and coagulation, as it can activate the coagulation cascade. High levels of its soluble form (sCD40L) that are observed in patients with IBD are an independent risk factor for thrombotic events in this population. ${ }^{14}$

Additionally, it is highly probable that the diminished barrier function of the inflamed bowel plays a role in the occurrence of ensuing autoimmune phenomena. There are reports of a higher incidence of idiopathic thrombocytopaenia and autoimmune haemolytic anaemia in patients with IBD,${ }^{15}$ in most cases as a second entity following episodes of bowel inflammation. It has been speculated that the higher permeability for pathogens of the bowel leads to the production of antibodies and to cross-reactivity with structural proteins of the body (antigenic mimicry).

Whether and how the two entities of TTP and idiopathic jejunoileitis in our case are pathophysiologically linked cannot be further clarified at this point. However, such a link is implied by the clinical course and should be the basis for further research. Considering the lack of data from clinical trials regarding a potential treatment-a gap that due to the rarity of this entity will likely not be filled in the future either-response to TNF-alpha blockade as described in our report is a potentially life-saving intervention for selected cases.

\section{Author affiliations}

${ }^{1}$ Department II of Internal Medicine and Center for Molecular Medicine Cologne, University of Cologne, Faculty of Medicine and University Hospital Cologne, Cologne, Germany

${ }^{2}$ III. Department of Medicine, University Medical Center Hamburg-Eppendorf, Hamburg, Germany

${ }^{3}$ Department of Gastroenterology and Hepatology, University of Cologne, Cologne, Germany

${ }^{4}$ Institute of Diagnostic and Interventional Radiology, University of Cologne, Cologne, Germany

${ }^{5}$ Department of Pathology, University of Cologne, Cologne, Germany
Acknowledgements The authors acknowledge the support and recommendations in the patient's treatment by Dr Boris Böll and Dr Fabian Kütting.

Contributors FB, VS and JD were the patient's primary physicians. SH and AQ interpreted the histological and radiological diagnostics, prepared and provided figures. TB, R-UM and DN supervised the treatment. FB and VS wrote the manuscript. All authors revised the manuscript.

The authors have not declared a specific grant for this research from any funding agency in the public, commercial or not-for-profit sectors.

Competing interests None declared.

Patient consent for publication Obtained.

Provenance and peer review Not commissioned; externally peer reviewed.

Open access This is an open access article distributed in accordance with the Creative Commons Attribution Non Commercial (CC BY-NC 4.0) license, which permits others to distribute, remix, adapt, build upon this work non-commercially, and license their derivative works on different terms, provided the original work is properly cited, appropriate credit is given, any changes made indicated, and the use is non-commercial. See: http://creativecommons.org/licenses/by-nc/4.0/.

\section{REFERENCES}

1. Enns R, Lay T, Bridges R. Use of azathioprine for nongranulomatous ulcerative jejunoileitis. Can J Gastroenterol 1997;11:503-6.

2. Freeman M, Cho SR. Nongranulomatous ulcerative jejunoileitis. Am $J$ Gastroenterol 1984;79:446-9.

3. Saxon A, Stevens RH, Ashman RF, et al. Dual immune defects in nongranulomatous ulcerative jejunoileitis with hypogammaglobulinemia. Clin Immunol Immunopathol 1977;8:272-9.

4. Corlin RF, Pops MA. Nongranulomatous ulcerative jejunoileitis with hypogammaglobulinemia. clinical remission after treatment with -globulin. Gastroenterology 1972;62:473-8.

5. Seven G, Assaad A, Biehl T, et al. Use of anti tumor necrosis factor-alpha monoclonal antibody for ulcerative jejunoileitis. World $J$ Gastroenterol 2012;18:5135-7.

6. Saud B, Nandi J, Ong G, et al. Inhibition of TNF- $\alpha$ improves indomethacin (indo)-induced jejunoileitis in rats by modulating iNOS expression. Am J Gastroenterol 2003;98:S261.

7. Roriz M, Landais M, Desprez J, et al. Risk factors for autoimmune diseases development after thrombotic thrombocytopenic purpura. Medicine 2015;94.

8. Almogy G, Sachar DB, Gans WH, et al. Ulcerative colitis and thrombotic thrombocytopenic purpura. J Clin Gastroenterol 2001;32:248-50.

9. Schleinitz N, Faure V, Bernit E, et al. Autoimmune thrombotic thrombocytopenic purpura: a severe complication of inflammatory bowel disease. J Clin Gastroenterol 2003;36:83.

10. Yuhara $\mathrm{H}$, Steinmaus $\mathrm{C}$, Corley D, et al. Meta-analysis: the risk of venous thromboembolism in patients with inflammatory bowel disease. Aliment Pharmacol Ther 2013;37:953-62.

11. Irving PM, Macey MG, Shah U, et al. Formation of platelet-leukocyte aggregates in inflammatory bowel disease. Inflamm Bowel Dis 2004;10:361-72.

12. Karpman D, Andreasson A, Thysell H, et al. Cytokines in childhood hemolytic uremic syndrome and thrombotic thrombocytopenic purpura. Pediatr Nephrol 1995;9:694-9.

13. Rivkin A. Thrombotic thrombocytopenic purpura induced by metronidazole vaginal gel. Pharmacotherapy 2007;27:1058-61.

14. Owczarek D, Cibor D, Głowacki MK. Inflammatory bowel disease: epidemiology, pathology and risk factors for hypercoagulability. World J Gastroenterol 2014;20:53-63.

15. Danese S, Katz JA, Saibeni S, et al. Activated platelets are the source of elevated levels of soluble CD40 ligand in the circulation of inflammatory bowel disease patients. Gut 2003;52:1435-41. 